\title{
Gestão de Marca: A qualidade percebida nas embalagens dos produtos
}

\author{
Machado, A. P.; Cardoso, H.; Perassi, R.
}

\section{RESUMO}

Este artigo trata mais especificamente dos aspectos perceptuais e informativos das embalagens. Mas, também, assinala sua funcionalidade, como parte do processo de identificação da marca e de percepção da qualidade. Para a gestão da marca, a coerência dos valores e a qualidade em geral devem ser predominantemente percebidas em todos os processos, produtos ou outras manifestações relacionadas à marca. Qualidade é um atributo necessário para a consolidação positiva da imagem da marca na mente do público consumidor, sendo decisiva na conquista da brand equity e do bonus price. Como ponto de contato da marca com o público, a embalagem dos produtos é, também, suporte para aplicação da mensagem gráfica da marca e de outras informações pertinentes. Porém, de acordo com seus valores e posicionamento, a comunicação da qualidade da marca ocorre, ainda, através de seus elementos estruturais e materiais. Os aspectos sensoriais do material usado, o volume, o formato e a usabilidade da embalagem participam do processo de identificação da marca e expressam qualidade. Além do potencial estético-simbólico dos materiais e do uso imediato das embalagens, o seu devir no contexto sócio-ambiental também assume valor simbólico. Pois, há uma parcela do público que se preocupa com processos sustentáveis de produção, reutilização e descarte de produtos e embalagens. Portanto, como aspectos estratégicos no contexto da gestão da marca, o projeto, a produção, a distribuição, a apresentação e o descarte das embalagens, compõem um percurso de qualificação da marca e do produto que essa representa. Neste texto, são apresentados e discutidos exemplos nos quais a visualidade das embalagens, tradicionalmente, foi destacada como diferencial competitivo.

Palavras chave: Brand Equity, qualificação, sensorialidad,. percepçã e embalagem.

\section{INTRODUÇÃO}

A maioria dos produtos com os quais nos relacionamos são comercialmente ofertados em embalagens. Mais especificamente, trata-se aqui de embalagens desenvolvidas e percebidas como elementos de identificação da marca, além de cumprir a função de acondicionar um produto, protegendo-o e identificando-o. Assim como outros tipos de embalagens comerciais, essas são também reconhecidas como canal de comunicação publicitária. Pois, apresentam, divulgam e promovem o produto e, principalmente, sua marca.

Além do produto que é acondicionado, a embalagem caracteriza-se também como um produto, cujas funções práticas são de preservação, armazenamento e transporte e a função simbólico-comunicativa é desenvolvida para valorizar o produto acondicionado e também sua marca. Portanto, a comunicação visual 
da embalagem agrega valores estético-simbólicos ao produto e à sua marca, contribuindo com a percepção de qualidade que caracteriza um aspecto necessário à promoção da brand equity.

Para Martins (2006, p.35), brand equity “é tudo aquilo que uma marca possui, de tangível e intangível, e que contribui para o crescimento sustentado dos seus lucros". Destaca-se entre os valores intangíveis a percepção de qualidade da marca, como resultante da percepção de qualidade em diferentes aspectos dos produtos e serviços oferecidos ao público consumidor. Isso inclui, também, aspectos da qualidade percebida nas embalagens.

Negrão e Camargo (2007) ressaltam a participação das embalagens nos processos de apresentação, promoção e comercialização dos produtos e das marcas, considerando que cerca de 70\% dos produtos são atualmente comercializados em embalagens. Portanto, é necessário que as embalagens sejam consideradas no processo de gestão da marca ou branding, indicando o projeto de embalagens como campo estratégico na qualificação do produto e, especialmente, da marca. Pois, é a marca expressa na embalagem que, simbolicamente, identifica, distingue e endossa o desempenho do produto na prateleira, antes mesmo que ocorra a experiência de uso.

No processo de projetação, primeiramente, considera-se os aspectos funcionais que garantem a qualidade do acondicionamento, visando manter a integridade do produto. Considera-se, também, a viabilidade do transporte, visando a segurança do produto e o conforto do usuário, nos processos logísticos de distribuição, armazenamento e consumo. Mas, quando experimentada por distribuidores e consumidores, a eficiência ou a ineficiência funcional se estabelece, também, como valor simbólico. Por exemplo, a adjetivação nominal de uma embalagem como "eficiente" ou "confortável" caracteriza uma atribuição positiva de valor.

Antes mesmo de usufruir as características funcionais e simbólicas, contudo, o público entra em contato com aspectos sensório-visuais, que denotam formas, cores, tonalidades, texturas e volumes. Essa visão sugere, ainda, ritmos, movimentos, profundidade, equilíbrio visual e proporcionalidade, entre outras possibilidades de sentidos visuais (PERASSI, 2010). Assim, em decorrência (1) da percepção do material utilizado na embalagem, (2) das relações estético-sintáticas decorrentes da composição visual impressa e (3) de outros tratamentos da produção, as embalagens são apresentadas como campo estético-sintático de estímulos sensório-visuais. Os estímulos percebidos despertam diversos sentimentos no público, influenciando diretamente o processo de qualificação estético-simbólico do produto e de sua marca.

O objetivo deste trabalho, portanto, é descrever o percurso de construção da qualidade percebida do produto e de sua marca, no contexto do branding, partindo dos estímulos sensório-visuais das embalagens.

A imagem visível da embalagem é relacionada à imagem da marca, como imagem mental decorrente dos esforços da corporação, para expressar uma identidade positiva junto ao mercado e ao público. A imagem de marca decorre das associações e interpretações que o consumidor estabelece e conecta a uma determinada marca (PINHO, 1996).

A identidade corporativa é parcialmente expressa na identidade visual da marca gráfica, dos produtos, das embalagens e de diversos produtos gráficos, como rótulos e outros elementos publicitários. A identidade visual auxilia na expressão da identidade corporativa, conectando a marca da organização com 
nomes, imagens e ideias, promovendo a consistência da comunicação visual e servindo de fio condutor para a construção do patrimônio simbólico da marca ao longo do tempo (WHEELER, 2008).

Do ponto de vista de Design Gráfico, a identidade visual é composta da assinatura visual, com seus elementos: logotipo e símbolo gráfico, além de apresentar cores, tipografias e outros elementos gráficos que identificam visualmente a marca. Esses elementos gráficos são aplicados em diferentes produtos de propaganda, como cartazes, outdoors e anúncios, e na comunicação corporativa, como a sinalização e a folhetaria da marca corporativa, aparecendo em ambientes físicos e virtuais, mas também em uniformes, veículos e fachadas de edifícios e, especialmente em embalagens e rótulos de produtos (PONTES, et. al., 2009).

Além dos produtos gráfico-comunicativos, entretanto, as características estruturais e visuais dos próprios produtos comerciais ou de suas embalagens, também, são percebidas como aspectos identificadores e distintivos da marca. São casos clássicos: (1) a configuração do automóvel da marca Volkswagen; (2) a garrafa do refrigerante Coca-Cola, e (3) as embalagens do produto vodka Absolut. Portanto, considera-se também que, do ponto de vista de Design de Produto, a estruturação sensorial e, especialmente, a visualidade de produtos e embalagens participa da identidade da marca, colaborando na construção positiva da imagem da marca na mente do público, como fator de distinção e expressão de qualidade.

\section{GESTÃO DA MARCA E IDENTIDADE}

A marca pode ser sintetizada por um elemento que representa, sinaliza e identifica organizações e produtos diante do público, podendo ser “(...) nome, termo, sinal, símbolo ou desenho, ou uma combinação dos mesmos, que pretende identificar os bens e serviços de um vendedor ou grupo de vendedores e diferenciá-los daqueles dos concorrentes" (PINHO, 1996, p.13).

A marca gráfica é, geralmente, composta por um logotipo, que é o nome da marca grafado de maneira específica, e por um símbolo, como uma imagem gráfica. Além da marca gráfica, há cores, tipografias e outros elementos visuais que caracterizam o conjunto de identificação da marca.

A imagem da marca é composta pelo conjunto de todas as associações afetivas e cognitivas que são recorrentes nas mentes do público com relação à marca e tudo o que essa representa. A marca gráfica se apresenta como a síntese gráfico-visual da identidade da marca, para os emissores da marca, e da imagem da marca para o público em geral.

(Marca é) um nome, normalmente representado por um desenho (logotipo e/ou símbolo) que, com o tempo, devido a experiências reais ou virtuais, objetivas ou subjetivas, que vamos relacionando a ela, passa a ter um valor específico, reforçando dessa forma a identidade visual da marca e consequentemente sua imagem (STRUNCK, 2007, p.18).

Inicialmente, as marcas foram desenvolvidas sobre a reputação dos produtos, porque desde a antiguidade, sua função foi marcar e identificar produtos, sendo que o bom desempenho desses produtos e 
seu uso por pessoas distintas na sociedade passaram a qualificar algumas marcas como símbolos de qualidade. Na mesma época teve início a cultura visual das marcas. Pois, devido ao analfabetismo do público em geral, tornou-se comum o uso de desenhos ou pinturas para identificar os produtores e os comerciantes das mercadorias (PINHO, 1996).

Marca é a soma intangível dos atributos de um produto; seu nome; embalagem e preço; sua história; reputação e maneira como ele é promovido. A marca é também definida pelas impressões dos consumidores sobre as pessoas que a usam; assim como pela sua própria experiência pessoal (OGLIVY, 2001 p. 35).

A preocupação com a qualidade e especificações técnicas já era presente na Idade Média. De modo ainda primitivo, havia o uso das marcas como elementos de controle de quantidade e qualidade de produção. Depois, houve a criação das marcas individuais, permitindo a preservação do monopólio e a identificação de falsificações. 0 comércio era feito longe do centro produtor, assim a marca era o elemento que estabelecia o vínculo distante entre o consumidor e o fabricante, sediado na cidade de origem do produto. Assim, o comprador tinha como se assegurar da qualidade do produto que adquiria, sabendo onde reclamar sobre uma eventual insatisfação (PINHO, 1996).

A partir da segunda metade do século XIX, diante do surgimento de produtos inventados, como rádio, carro ou lâmpada elétrica, as campanhas publicitárias adotaram como foco informar os consumidores sobre a existência desses novos produtos e convencê-los de que sua vida seria melhor se os usassem. 0 fato de ser uma novidade já contava como publicidade positiva a seu favor. Quando os produtos passaram a ser produzidos em fábricas, tanto os produtos inventados quanto os produtos alimentícios entraram nessa nova forma de produção (KLEIN, 2002).

Progressivamente, entretanto, a boa reputação do produto ou serviço passou a ser representada pela marca, sendo que isso possibilitou a extensão da marca, como garantia de qualidade para novos produtos. Portanto, antes mesmo de conhecer um produto, o público passou a se dispor a experimentá-lo, confiando na sua marca como símbolo de qualidade.

Um dos exemplos pioneiros do uso da marca como elemento simbólico de diferenciação aconteceu na Escócia, em 1835. Pois, na época, houve a criação da marca Old Smuggler, cujo nome associava a bebida whisky, que era produzida pela marca, aos produtos trazidos por contrabandistas, porque a bebida contrabandeada era considerada de excelente qualidade. Nesse caso, portanto, o nome da marca influenciava a percepção do produto, invertendo a tradição de que o desempenho dos produtos qualificava a marca.

Atualmente, os nomes e os outros elementos publicitários que expressam a marca, incluindo as embalagens e a aparência dos produtos, são pensados e desenvolvidos para promoverem a qualidade percebida, atuando como elementos que simbolizam a qualidade do produto. A marca é uma entidade pública, intersubjetiva e intangível, cujos valores são expressos nos mais diversos elementos e aspectos que lhe são relacionados. Todo o conjunto expressivo da marca, incluindo os próprios produtos e serviços que essa representa, é projetado para bem impressionar o público e atender suas expectativas de consumo, sejam essas objetivas ou subjetivas. 
A marca é a promessa, a grande ideia e as expectativas que residem na mente de cada consumidor a respeito de um produto, de um serviço ou de uma empresa. As pessoas se apaixonam pelas marcas, confiam nelas, são fiéis a elas, compram e acreditam na sua superioridade. A marca é como a escrita manual. Ela representa alguma coisa (WHEELER, 2008, p.12).

A marca é considerada, portanto, um sistema no qual interagem elementos e aspectos tangíveis e intangíveis, porque se expressa em coisas materiais e objetivas e simboliza coisas imateriais e subjetivas. As coisas materiais podem ser percebidas e registradas, como é o caso da marca gráfica, que é igualmente reconhecida como marca registrada. Os produtos e suas embalagens, também, podem ser percebidos e protegidos, assim como diversos outros itens materiais que expressam a marca. Porém, esses elementos tangíveis simbolizam conceitos, valores e afetos, os quais compõem a imagem da marca na mente do público, sendo que a síntese gráfica de toda a cultura da marca é a marca gráfica.

(Marca) é a união de atributos tangíveis e intangíveis, simbolizados num logotipo, gerenciados de forma adequada e que criam influência e geram valor. Trata-se de um sistema integrado que promete e entrega soluções desejadas pelas pessoas (MARTINS, R., 2008, p.08).

Como sistema simbólico, a marca é composta e desenvolvida através de uma ampla rede de comunicação com os stakeholders e o público em geral. A rede dispõe de canais, veículos e mensagens oficiais e extra-oficiais, que atuam constantemente no processo comunicativo. Os elementos oficiais podem ser diretamente controlados, todavia, os extra-oficiais devem ser gerenciados e manejados com processos de informação e contra-informação, que são propostos através de canais, veículos e mensagens oficiais da marca.

\subsection{GESTÃO DA MARCA OU BRANDING}

A área que se propõe a gerenciar a comunicação da marca é denominada de Gestão da Marca ou Branding. Pois, o que assegura o êxito no mercado, não é apenas o fato de um produto ou serviço ter uma marca. Atualmente, é necessária a construção e o constante desenvolvimento da marca, porque não faltam opções de produtos similares, que dependem de distinção simbólica. A marca é uma entidade que distingue e endossa produtos e serviços. Sendo assim, a marca necessita desenvolver uma identidade coerente e uma reputação sólida. Para tanto, é necessária a gestão da marca, visando refinar a identidade e desenvolver positivamente a reputação da marca.

O trabalho do branding é direcionado ao controle das características físicas dos elementos expressivos da marca, considerando o material publicitário-promocional e, também, os aspectos perceptíveis de pontos de venda, veículos, uniformes, embalagens, produtos e comportamentos de colaboradores, entre outros. $\mathrm{O}$ controle dos aspectos físicos visa influenciar de maneira eficiente a percepção, as interpretações e as emoções dos stakeholders e do público em geral. Mais especificamente, 
consiste no planejamento dos estímulos expressivo-comunicativos, em busca de respostas comportamentais positivas.

(Branding é) uma expressão para designar as tarefas voltadas para os processos de desenvolvimento, criação, lançamento, fortalecimento, reciclagem e expansão de marcas. (...) pode ser definido, então, como o conjunto das tarefas de marketing - incluindo suas ferramentas de comunicação - destinadas a otimizar a gestão das marcas (SAMPAIO, 2002, p. 27).

A Gestão de Marca ou Branding diz respeito a tudo o que se relaciona ao universo da marca, tratando de sua construção e gerenciamento, tudo isso com o objetivo de “(...) criar uma imagem única e positiva - para um produto ou serviço" (GRACIOSO, 2004, p.06). Para tanto, gerencia os valores e atributos da marca, considerando aspectos tangíveis e intangíveis, para construir a imagem da marca de maneira coerente e positiva, visando para estabelecer o brand equity.

Brand Equity é o conjunto de ativos e passivos ligados a uma marca, seu nome e seu símbolo, que se somam ou se subtraem do valor proporcionado por um produto ou serviço para uma empresa ou para os consumidores dela. (...) Podem ser agrupados em 05 categorias: lealdade à marca, conhecimento do nome, qualidade percebida, associações à marca em acréscimo à qualidade percebida, outros ativos do proprietário da marca (patentes, trademarks, relações com os canais de distribuição) (AAKER, 1998, p.16).

Brand Equity está relacionado ao valor da marca junto ao público usuário ou consumidor, promovendo maior lealdade, menor vulnerabilidade, possibilitando preços diferenciados e maiores margens de lucro. Isso diferencia uma marca de valor com relação à oferta de outras marcas e aos serviços e produtos commodities. Portanto, "representa uma condição em que o consumidor é familiar à marca, sobre a qual guarda associações favoráveis, únicas e muito fortes” (MARTINS, R.2008, p.200).

A busca por brand equity é necessária nos dias de hoje, porque qualifica a gestão da marca diferenciando-a objetivamente no mercado. Isso é relacionado ao desempenho dos serviços e dos produtos. Mas, também, considera a ampla percepção do público com relação aos atributos e benefícios intangíveis, que influenciam na escolha da marca, especialmente, no momento da compra.

Brand Equity considera: (1) a lealdade a marca; (2) o conhecimento da marca; (3) a qualidade percebida, e (4) as associações da marca. “A construção do brand equity realiza-se, então, pela criação de um conjunto organizado de atributos, valores, sentimentos e percepções que são conectados à marca, revestindo-a de um sentido de valor, que ultrapassa o custo percebido dos benefícios funcionais do produto" (PINHO, 1996, p.47).

Diante da lealdade à marca, os concorrentes se sentem desencorajados a investir para tentar atrair os consumidores que são considerados leais e satisfeitos. 0 conhecimento da marca permite o benefício decorrente do fato de que o consumidor tende a preferir o produto que lhe é familiar, porque reconhece positivamente sua marca. A qualidade percebida influencia na compra e na fidelidade à marca, 
possibilitando também a cobrança de preços mais elevados ou premium price. As associações positivas relacionam a marca com aspectos ou personalidades, que são positivamente percebidas, reforçando sua imagem positiva.

A percepção de qualidade é desenvolvida a partir de informações que, geralmente, antecedem à utilização de um produto ou um serviço. Pois, o valor da marca é rapidamente disseminado na cultura por inúmeras mensagens que, às vezes, antecedem à própria existência do produto ou serviço. Isso é comum quando uma marca lança um novo produto ou serviço. Porém, há também situações em que pessoas experimentam um produto ou serviço já existente, mas somente depois de ouvir comentários ou receber informações que anunciam sua qualidade.

Por outro lado, produtos sobre os quais não foram obtidas informações prévias, também, são previamente avaliados por sua própria aparência ou pela aparência dos elementos de sua publicidade. Entre esses últimos, destacam-se as embalagens. Diante de dois produtos desconhecidos ou que os valores das marcas e dos produtos parecem semelhantes para o consumidor, a decisão de compra pode ser baseada na qualidade proposta pela aparência das embalagens ou dos próprios produtos.

\subsection{IDENTIDADE E IMAGEM DA MARCA}

A marca se estabelece como uma entidade físico-simbólica. 0 corpo expressivo é composto pela materialidade dos elementos tangíveis que compõem os processos gerencial, produtivo, comunicativo e de consumo. Isso inclui os produtos de comunicação e os produtos de consumo, sendo que, entre esses, destacam-se as embalagens. 0 acervo simbólico é composto pelo conjunto de lembranças de sensações, sentimentos e ideias relacionadas diretamente e indiretamente à marca.

Como entidade simbólica, a marca desenvolve uma cultura e uma identidade, de acordo com suas possibilidades de existência e atuação, sob o direcionamento dos gestores. 0 público interno e parte do público consumidor externo participam de um processo de identificação com a marca, passando a sentir-se representado por ela. Geralmente, essa identificação não é completa, permitindo a composição de uma imagem da marca, que distingue a percepção da marca da auto-imagem do indivíduo, seja esse componente do público interno ou externo.

A identidade é expressa por si mesma em cada ponto de contato da marca e se torna intrínseca para a cultura de uma empresa - uma lembrança constante de seus valores fundamentais e de sua tradição. (...) demonstra, mais do que declara, um ponto de vista único, desde a interface de um website, passando pelo design de um produto, até a experiência de venda em uma loja. (WHEELER, 2008, p.22)

A identidade da marca é decorrente do processo interno de sua gestão. A identidade oficial é conscientemente planejada e expressa através dos processos oficiais de comunicação da marca. Já a imagem da marca é desenvolvida de acordo com o modo como os públicos, interno e externo, percebem e consideram a marca, a despeito do que oficialmente comunicado. 
Imagem é a maneira como o público percebe a empresa ou seus produtos. É conduzida por todos os tipos de mídia e leva tempo para ser implantada na mente do consumidor. (...) Identidade compreende as formas adotadas por uma empresa para identificar-se ou posiciona seu produto. Deve ser mostrada repetidamente e fazer parte de todas as comunicações da empresa (MARTINS, R., 2008, p.135).

Assim, o êxito da gestão da marca está em gerenciar os processos de expressão e comunicação da marca de maneira a reduzir ao máximo a distância entre o modo como a marca foi planejada para ser percebida (identidade) e o modo como essa é efetivamente percebida pelo público (imagem).

Expressar que tipo de organização você é; garantir ao público que você realmente é aquilo que diz ser, conectar sua empresa a imagens e ideias, servir como fio condutor para construir patrimônio ao longo do tempo e posicionar consistência nos canais de comunicação (WHEELER, 2008, p.14).

A identidade da marca é comunicada por diferentes elementos, sendo que a distinção e recorrência de cores e de tipografias específicas, entre outros elementos como o logotipo e o símbolo gráfico, compõem a identidade gráfico-visual da marca. A marca gráfica ou marca registrada é a síntese gráficovisual da identidade oficial da marca. Cores e símbolos da marca são reproduzidos e expressos nos pontos de vendas, nos depósitos, nos veículos, nos uniformes e em diversos outros elementos relacionados à marca, sendo também comumente reproduzidos nos produtos e em suas embalagens. As características perceptíveis que são distintivas dos produtos e das embalagens, entretanto, apresentam-se igualmente como expressões da identidade da marca e, também, influenciam de maneira determinante a composição da imagem da marca na mente do público.

\section{EMBALAGEM E MARCA}

\subsection{EMBALAGEM}

Negrão e Camargo (2009) assinalam que a qualidade do design e o número de embalagens no Brasil são semelhantes à produção dos países desenvolvidos. 0 desenvolvimento e a produção de embalagens mais que duplicou depois do ano de 2000. Há milhares de embalagens diferentes, tendo sido observados mais de sete mil itens diferenciados, cuja produção gerou no ano de 2007 um faturamento em torno de 30 bilhões de reais (NEGRÃO e CAMARGO, 2009).

Embalagem é um produto cuja função prática é acondicionar e proteger outros produtos, para garantir sua integridade. Assim, promove melhores condições de armazenamento e transporte, contribuindo na viabilização dos processos de distribuição, venda e uso ou consumo dos produtos.

A embalagem, entretanto, pode também ser usada como suporte e veículo de mensagens, as quais orientam sobre seu próprio manejo ou, também, orientam sobre o uso do produto acondicionado. A embalagem ainda desempenha função simbólica ao ser estruturada e apresentada de maneira distinta, para 
atuar como símbolo de determinada marca ou produto. Além disso, pode suportar e veicular os elementos de identificação gráfico-visual da marca e as imagens do produto, entre outras possibilidades.

Além das funções protetoras, a embalagem permite distribuição, venda e uso dos artigos, valendo ressaltar que o maior sistema de vendas, o supermercado que, no Brasil, corresponde a $82 \%$ do varejo, ó é viável pela existência da embalagem vendedora. Como sabemos, a embalagem substitui o vendedor no auto-serviço, reduzindo o custo da venda em cerca de 30\%. A embalagem é chamada de "vendedor silencioso". Por outro lado, foram as exigências do supermercado que mais contribuíram para o desenvolvimento da tecnologia e do design da embalagem (NEGRÃO E CAMARGO, 2008, p.15).

Depois da aquisição do produto, o consumo da embalagem costuma ser rápido, porque a preservação da embalagem pelo consumidor ocorre em situações específicas, sendo mais comum o descarte quase que imediato da embalagem. Atualmente, isso implica em outras questões de ordem prática e simbólica, considerando a comodidade do consumidor e a sustentabilidade econômica e ecológica do uso da embalagem. Isso vem obrigando as empresas a reconsiderarem o processo de uso e descarte das embalagens. Por exemplo, depois de altos investimentos em embalagens descartáveis, as empresas de bebidas, entre outras, passaram a reconsiderar o uso de embalagens retornáveis ou de processos de recuperação e reciclagem das embalagens já utilizadas.

Diante disso, a política da marca com relação ao manejo das embalagens, também, passou a ser parte do processo de composição de sua imagem positiva diante do consumidor. A embalagem pode ser suporte de aplicação da marca, promovendo sua comunicação com o consumidor. Mas, também, está diretamente relacionada à marca, como elemento expressivo-comunicativo de sua identidade, de sua cultura e do seu posicionamento, diante do mercado e do público-consumidor.

(A embalagem) constitui a primeira aproximação visual pelo consumidor. Devido à multiplicação de marcas e produtos relativamente semelhantes, a embalagem é cada vez mais minuciosamente estudada, tendo que se renovar frequentemente diante da pressão da concorrência (MARTINS, R., 2008, p.72).

Para Martins (2006, p. 109), “a embalagem é o cartão de visitas da maioria das marcas e, dependendo do produto, é crucial”. Assim, quanto maior for seu impacto visual junto ao público-consumidor, mais pregnante é a experiência, maior é a possibilidade de lembrança, influenciando no processo de reconhecimento, escolha e compra do produto. Valorizar e desenvolver a embalagem, como elemento mediador da comunicação da marca e da compra do produto, requer conhecimentos sobre o mercado e, também, sobre as potencialidades e o comportamento do público consumidor.

A comunicação entre a embalagem e o público ocorre a partir de diversos aspectos expressivocomunicativos como: os materiais usados, a forma, o funcionamento, as informações e a estética como um todo, entre outros. Quando essas características são distintivas, as mesmas são percebidas como expressões da marca. Assim, “o design desempenha um papel fundamental para assegurar que a percepção dos 
consumidores da marca esteja espelhada na embalagem" (CALVER, 2009, p.07).

O desenvolvimento da embalagem ocorreu em paralelo aos avanços das tecnologias de produção e ao aprimoramento dos transportes, seguindo as mudanças sociais. A embalagem foi adequada ao estilo de vida das pessoas, de acordo com seus interesses e necessidade. Por exemplo, embalagens são adaptadas para caber em bolsas femininas ou mochilas, sendo igualmente estruturadas para diversas atividades de trabalho, esporte ou lazer, considerando-se igualmente os aspectos funcionais e estilísticos das atividades.

\subsection{EMBALAGEM COMO EXPRESSÃO DA MARCA}

\subsubsection{A GARRAFA DO PRODUTO COCA-COLA}

Tradicionalmente, os rótulos e as embalagens são suportes do nome do produto e de outros elementos gráfico-visuais identificadores da marca, como cores e tipografia específica, entre outros. Porém, procura-se destacar neste artigo a possibilidade de estruturação físico-visual da embalagem, seu material, seu formato e sua cor, entre outros aspectos, como fatores identificadores e distintivos da marca. 0 exemplo clássico de embalagem como expressão da marca é a garrafa do produto Coca-Cola (Fig. 1), que é elemento identificador e distintivo amplamente reconhecido pelo público, como símbolo patrimonial da marca.

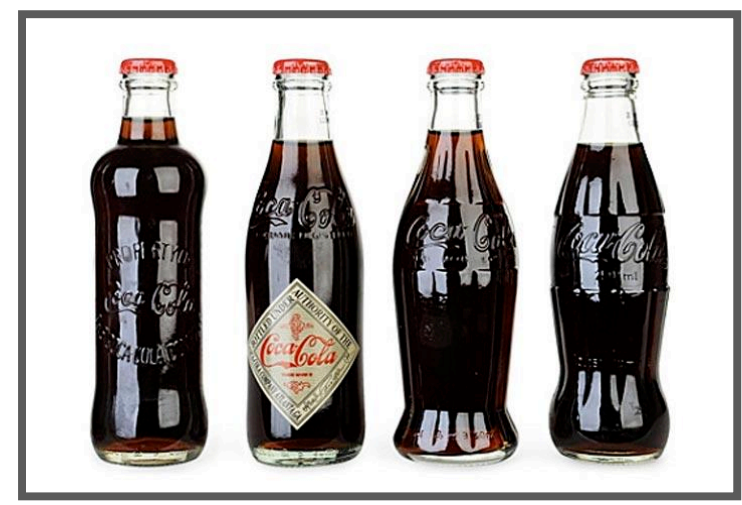

Figura 1. Evolução da garrafa do produto Coca-Cola até o formato clássico.

Fonte: Sítio Vidrado. Com.

O formato da garrafa clássica (Fig. 1) é o elemento típico da embalagem de Coca-Cola, que atua como aspecto identificador e distintivo da marca. A transparência da embalagem permite a expressão singular do produto que, apesar de escuro, expressa tonalidades translúcidas de marrom avermelhado. 0 corpo da embalagem apresenta o nome da marca e a tampa da embalagem é colorida com a cor vermelha, que é parte da identidade cromático-visual da marca. 


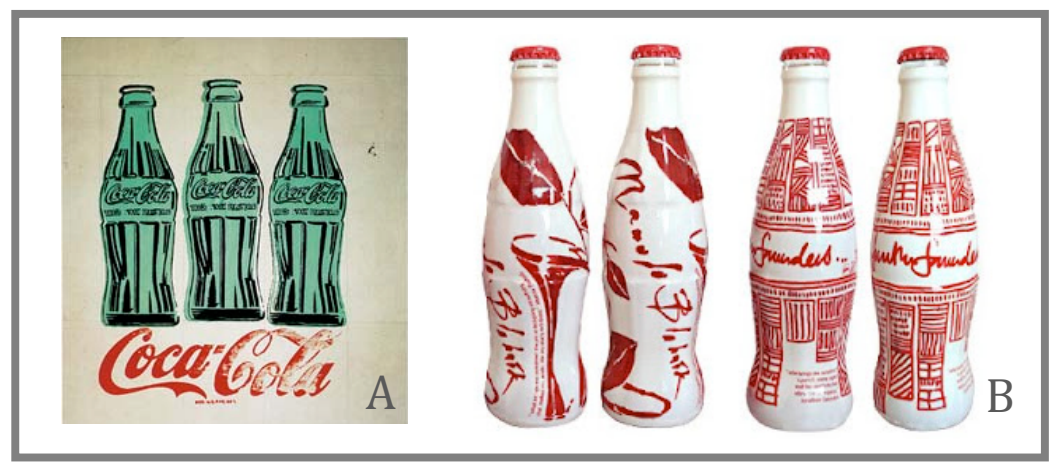

Fig. 2 - (A) Three Coke Botles - Serigrafia Pop de Andy Warhol - (B) Design de Manolo Blahnik Fonte: Sítio Wordpress

Além de expressar a marca, a embalagem do produto Coca-Cola é percebida como ícone da sociedade industrial e da indústria cultural do século XX, tendo sido representada e utilizada por diferentes artistas (Fig. 2-A), criticada por intelectuais de esquerda e cultuada por designers (Fig. 2-B), publicitários e profissionais de marketing.

\subsubsection{A LATA DO PRODUTO LEITE CONDENSADO MOÇA}

O produto leite condensado da marca Moça, foi o primeiro produto da fábrica Nestlé vendido no Brasil, estando aqui desde 1890. Sua embalagem em lata variou de formato entre o cilíndrico e o cilindro ondulado, apresentando também atualizações nas imagens que compõem os seus símbolos gráficos de identificação. Por exemplo, foram renovados os desenhos do logotipo e da figura-símbolo, que representa uma mulher jovem de avental e roupas antigas, segurando com a mão esquerda uma tina de madeira sobre a cabeça, enquanto segura outra tina com a mão direita (Fig. 3).

A partir de 2004, a ondulação no formato da marca, caracterizou-se como elemento de identificação da marca e, recentemente, estampas de latas antigas $(1937,1946,1957,1970$ e 1983) foram reeditadas em embalagens de formato ondulado, caracterizando edições comemorativas, que serão comercializadas até o final deste ano de 2012. As imagens das embalagens foram registradas e são apresentadas com a expressão "marca Moça” ou com o nome do produto "Moça” voltadas diretamente para um possível observador. Isso indica que, apesar de sua tridimensionalidade, há um campo visual pré-definido, que deve ser considerado e privilegiado no processo de exposição e na leitura da embalagem. 


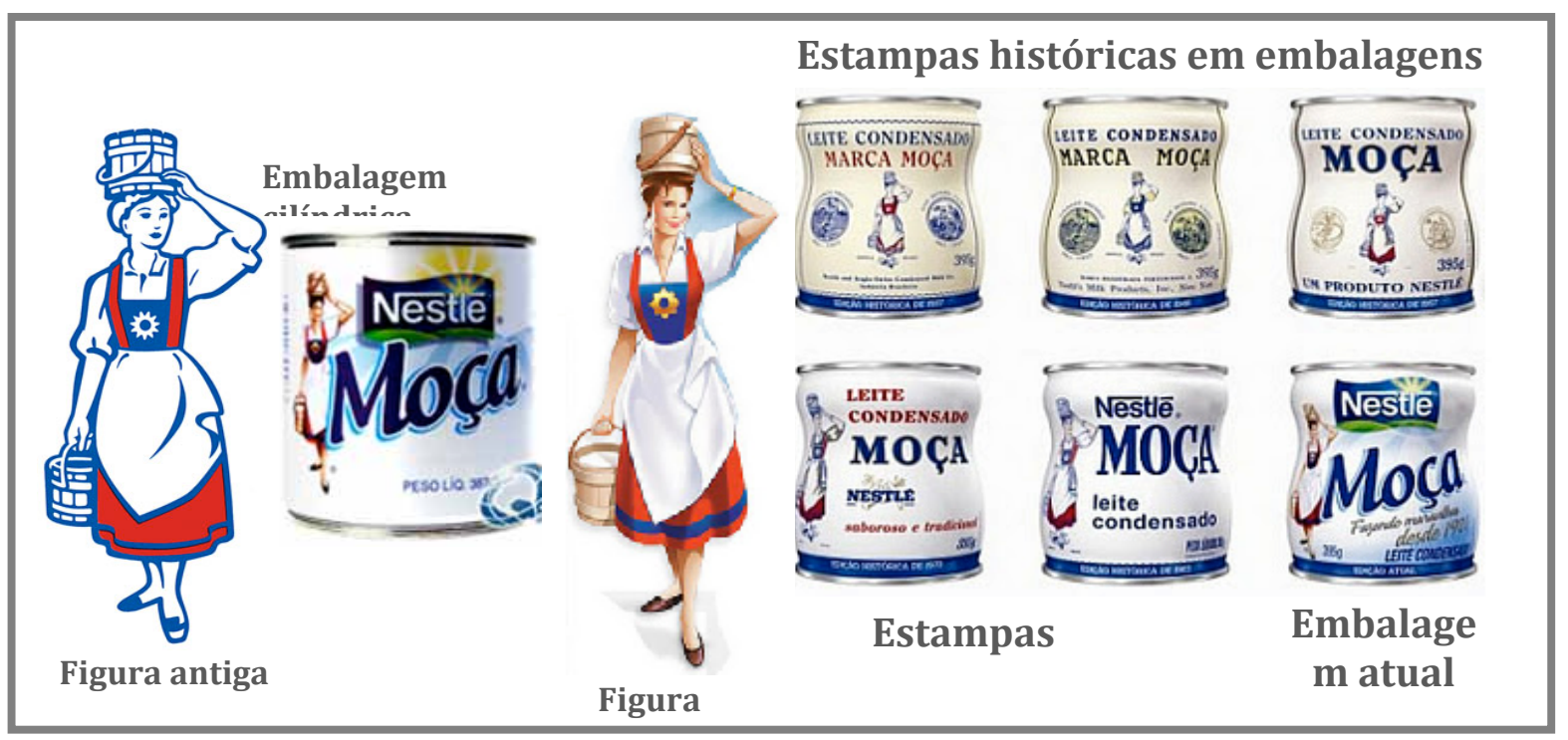

Fig. 3 - Elementos gráficos e embalagens do produto leite condensado "Moça”.

Fonte: Composição dos autores com imagens retiradas do sítio Nestlé.

Na versão mais recente da embalagem do produto leite Moça, que está no mercado desde 2004, o formato da mesma amplia a dinâmica proposta nas estampas, que já haviam sido modificadas anteriormente e propostas sobre a antiga embalagem cilíndrica (Fig. 3). Pois, nas estampas atuais, o logotipo da marca Nestlé aparece dentro de uma figura que representa uma bandeira, na cor azul-violeta escura, sendo que esta bandeira também sugere ondulação. Além disso, na parte superior da bandeira sobre a letra "L" do logotipo "Nestlé" aparece uma mancha amarela, sugerindo a figura do sol expandindo raios luminosos. 0 nome do produto Moça, impresso também com tinta azul-violeta escura, aparece inclinado com efeitos de sombra ou contorno em azul mais claro. A parte do fundo entre o nome do produto, "Moça", e a bandeira com o nome da marca, "Nestlé", sugere uma paisagem com montes verdes, cujos cumes são configurados na parte inferior da bandeira.

$\mathrm{Na}$ embalagem atual, a figura que representa a jovem aparece ondulada, devido ao volume do suporte, ampliando assim a sensação de movimento. $O$ formato da embalagem também propõe movimento às imagens estampadas, indicando em sua configuração sensualidade e feminilidade, que podem ser relacionadas às formas femininas.

A embalagem faz a mediação estético-simbólica entre a marca e o público em geral. Pois, esse entra em contato com sua visualidade e sua materialidade. Assim, há aspectos lingüísticos e figurativos, como o nome "moça" e outras palavras ou textos escritos, como também há representações figurativas: da mulher, dos montes, do sol e da bandeira. Mas, além disso, há o volume e a ondulação da embalagem; há o fundo predominantemente branco com nuanças suaves de azul; há a textura lisa ao toque e brilhante para visão, tendo em vista o material, a tinta e seus efeitos sensórios, como o contraste das cores: azul, verde e amarela sobre o fundo branco.

Observando as imagens das diferentes edições da embalagem e, também, as diferenças entre a representação da figura feminina antiga e a representação mais recente (Fig. 3), percebe-se a alteração no 
foco da informação-comunicação, na composição gráfica das embalagens

Nas composições mais antigas (Fig. 3), devido a aspectos culturais e a limites tecnológicos, o foco era configurado por objetividade e síntese, investindo-se mais na comunicação lógico-codificada. Isso é geometricamente proposto na organização simétrica e ortogonal da mensagem, com os textos escritos e os nomes paralelos à base de apoio da embalagem, sendo que a composição era organizada simetricamente, com relação a um eixo central virtual, demarcado pela representação da mulher no meio da composição (Fig. 3).

Na composição atual (Fig. 3), a representação da mulher foi atualizada e sua figura deslocada lateralmente, com relação ao campo visual da embalagem. A figura feminina antiga é mais estilizada, sendo representada por linhas e apresentando menor quantidade de informação, com relação à atual. Pois, na figura mais recente, as linhas foram suprimidas e as áreas brancas da figura antiga, como as representações de partes da roupa, da pele e de outros elementos, são recobertas com cores e tonalidades variadas, sugerindo efeitos tonais e cromáticos, que seriam decorrentes de variações de luz, sombra e volume. Além disso, a representação gráfica do nome do produto foi ampliada e inclinada. A marca Nestlé também foi ampliada e destacada, aparecendo recortada em branco sobre o fundo azul e verde da bandeira.

\subsubsection{A GARRAFA DO PRODUTO VODKA ABSOLUT}

A marca Absolut identifica o produto vodka que foi fabricado originalmente na Suécia, a partir do ano de 1879. 0 processo clássico de formulação e produção da bebida não oferece possibilidades de alterações distintivas no produto. Portanto, o argumento de qualidade é objetivamente estabelecido, considerando-se o cuidado na fabricação e a pureza do produto.

Do ponto de vista simbólico, o conceito de tradição não foi considerado um argumento válido, porque o produto da marca é proveniente de um país que não é, tradicionalmente, reconhecido como produtor vodka. Pois, os produtos do país Rússia são os mais tradicionais e reconhecidos na categoria vodka.

A falta de diferenciação e de tradição não impediu, entretanto, o sucesso da marca, considerando-se que as vendas do produto a fizeram líder do mercado mundial. Do ponto de vista objetivo, foi assinalada a pureza do produto, sendo que essa qualidade deve ser parcialmente confirmada na observação da perfeita transparência da garrafa que lhe serve embalagem. Por outro lado, houve também investimento criativo, privilegiando aspectos estético-simbólicos no design das embalagens e das campanhas publicitárias. Isso envolveu o produto e a marca em uma áurea de sofisticação e sedução.

De acordo com Schmitt e Simonson (2000), o sucesso da marca foi alcançado graças a uma campanha bem integrada de identidade, cujo tema propôs a marca como: "moderna, vistosa, elegante, sofisticada, às vezes tola, mas com estilo refinado". Assim, a campanha que transformou os pontos fracos do produto vodka Absolut em vantagens competitivas.

De modo geral, o posicionamento proposto apresenta uma marca jovem, internacional, contemporânea, imprevisível, fashion, criativa e espirituosa, na categoria de bebida alcoólica destilada e focada no público jovem. 0 design da embalagem clássica do produto vodka Absolut foi desenvolvido em 
1979, por uma equipe de designers suecos, tendo sido inspirado na embalagem de vidro do século XVIII, de um antigo produto medicinal.

Mesmo sem alcançar a proeminência cultural da garrafa de Coca-Cola, a embalagem de vidro do produto da marca Absolut, é considerada um ícone da cultura de mercado, relacionando Design, Marketing, Publicidade, Branding e, também, Arte. Pois, a garrafa serviu de suporte para criações visuais de artistas conceituados, através de um projeto desenvolvido em diferentes países, com artistas nacionais. Houve a edição americana e a francesa. Na edição brasileira do projeto (Fig. 4), artistas conhecidos como Nelson Leirner e Daniel Senise participaram do projeto, cujas obras foram expostas no ano de 2007 na cidade de São Paulo.

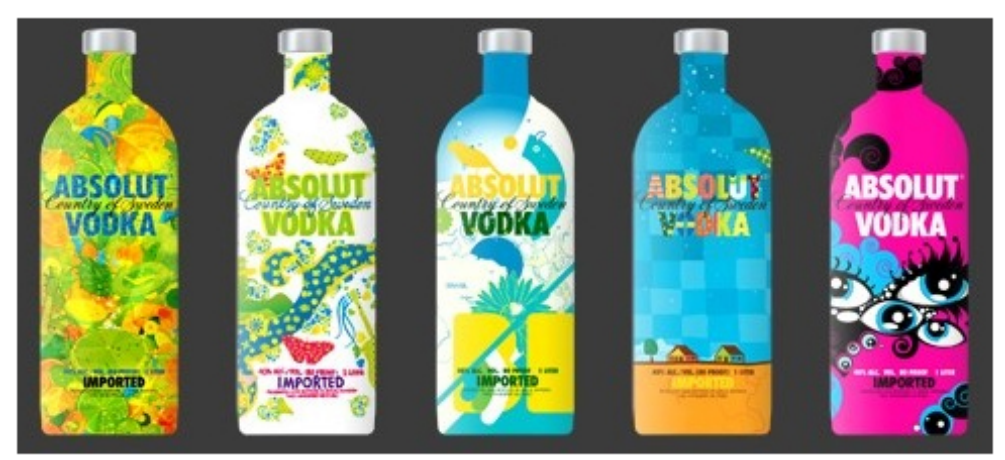

Fig. 4 - Embalagens do produto vodka Absolut com estampas de artistas. Fonte: Sítio Mundo do Marketing

Inicialmente, a garrafa foi considerada antiquada, como resquício de um laboratório de Alquimia. Porém, atualmente, a mesma garrafa é percebida como diferencial competitivo da marca Absolut (Fig. 5-A). 0 design da embalagem é percebido como identificação do produto e da marca Absolut, mesmo quando não há quaisquer outras referências simbólicas que o relaciona à marca, como acontece na edição sem rótulo, "no label" (Fig. 5-B).

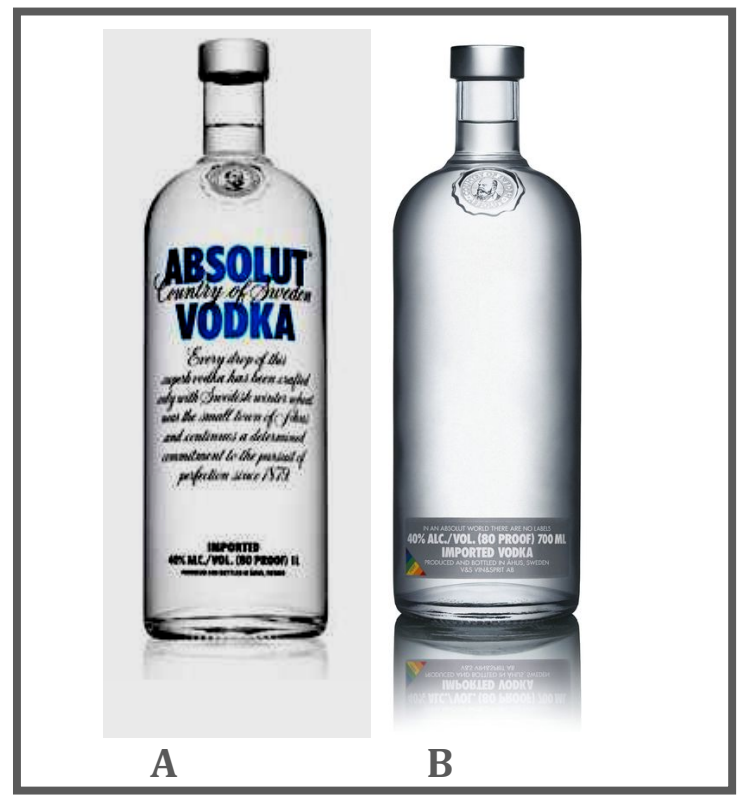

Fig. 5 - Embalagem clássica do produto vodka Absolut: A - com rótulo; B - sem rótulo. Fonte: Sítio Absolut 
Considerando os exemplos anteriores, na garrafa de Coca-Cola e na lata de leite condensado Moça, o corpo da embalagem evoluiu para o formato ondulado. Porém, o corpo da garrafa de vodka Absolut é perfeitamente cilíndrico, simétrico e transparente, expressando a estética minimalista. A parte superior do cilindro é configurada como cúpula, cujo centro recebe outro cilindro perfeitamente simétrico e transparente, que cumpre a função de gargalo. 0 rigor geométrico do corpo, do gargalo e da tampa cinzametálico da garrafa, sugere racionalidade e seriedade ou sisudez, propondo sua semelhança com embalagens de tempos mais antigos e severos.

O anacronismo e a seriedade são sentidos e também reforçados no timbre em relevo, que aparece no alto do corpo da garrafa. Além disso, a tipografia do rótulo apresenta letras retas, projetadas com rigor geométrico para compor o logotipo da marca, e também letras do tipo manuscrito, referindo-se a escrituras manuais do passado.

Em lojas e prateleiras de bares, a garrafa minimalista se destaca das demais, com pescoço longo e largo, onde se lêem as palavras ABSOLUT VODKA, estampadas no vidro em letras maiúsculas reforçam a imagem distinta do produto: básica, direta e sofisticada (SCHMITT e SIMONSON, 2000).

O projeto de Design da garrafa do produto vodka Absolut estabeleceu uma tendência no desenho das embalagens dos produtos vodka de outras marcas (Fig. 6). Pois, sua forma contrasta com as garrafas mais tradicionais, influenciando a estética e a sintaxe visual de outras embalagens, que foram redesenhadas ou projetadas em época posterior ao lançamento do produto Absolut.

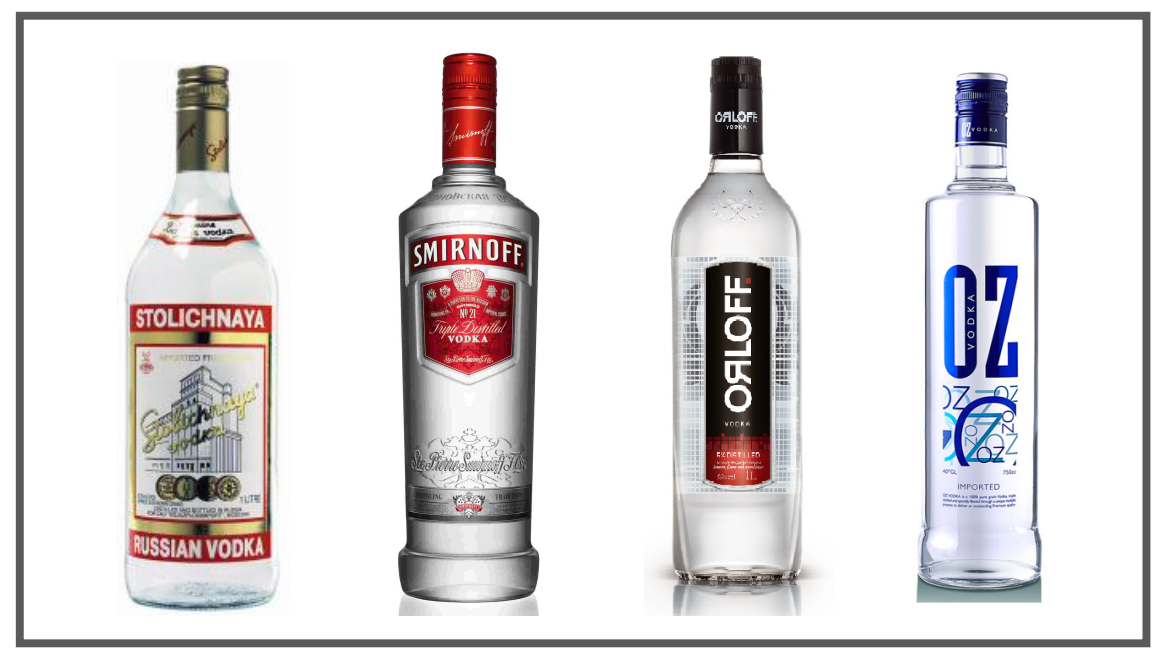

Fig. 6 - Uma imagem de garrafa tradicional (A) e três imagens de modelos mais estilizados (B, C, D).

Fonte: Sítio Globo Mídia

A percepção da embalagem do produto vodka Absolut, como principal símbolo da marca, é reforçada nas peças de comunicação publicitária (Fig. 6). Assim, diante das dificuldades para a diferenciação do produto, sua embalagem atua como elemento identificador e distintivo da marca e do produto, apresentando aspectos técnicos e estético-formais que, também, qualificam simbolicamente o produto. 0 conceito que 
posiciona a embalagem no processo de Branding ou de Gestão da Marca é expresso na frase: "a garrafa é a estrela".

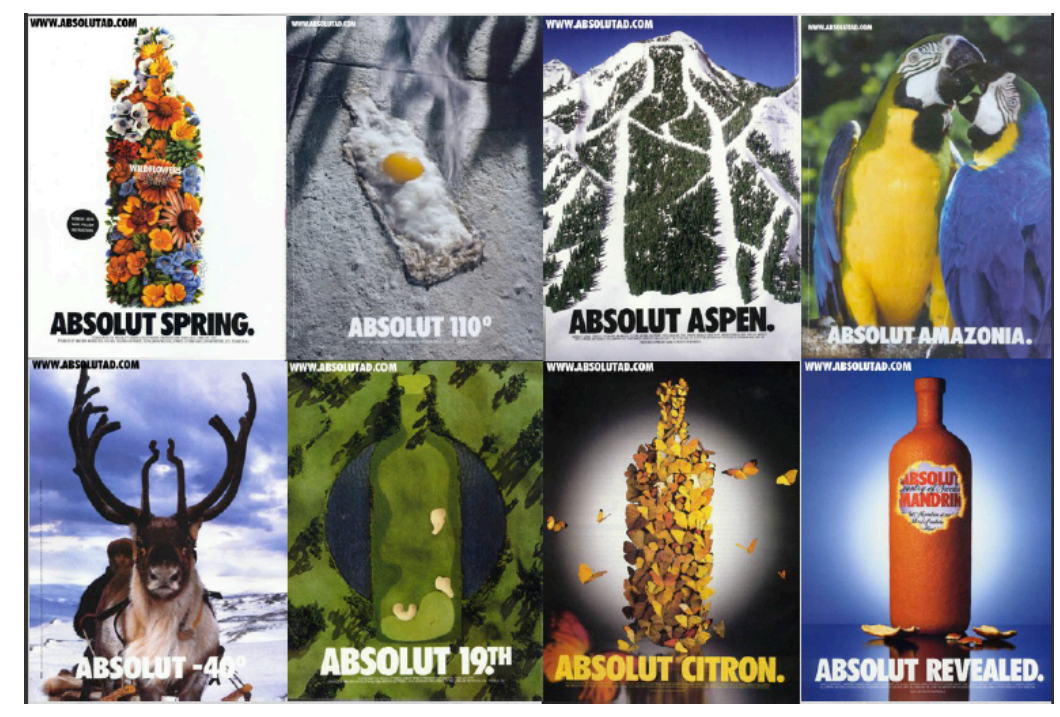

Fig. 6 - Cartazes da marca Absolut, apresentando a garrafa como elemento de identificação.

Fonte: Sítio Absolut

Considerando que a garrafa é a principal atração da marca, a partir de 2006, a embalagem de vidro do produto vodka Absolut passou a ser produzida com aspectos visuais diferenciados, caracterizando edições especiais do produto. Isso possibilitou a oferta da própria embalagem como produto para colecionadores, além de atuar como elemento de distinção e qualificação do produto. Houve uma edição de Natal e, em outra edição, a embalagem apresentou a superfície prateada e espelhada, como referência à cultura Dance Music. A edição sobre Rock Music foi desenvolvida em parceria com a marca de moda vestuário Ellus, compondo a coleção Ellus Absolut Rock (LOTI, 2010), como estratégia de co-branding.

\section{CONSIDERAÇÕES FINAIS}

A Escola de Negócios de Lausanne (IMD/Suíça) é um ponto de encontro mundial de negócios e, naquele contexto, foram identificadas três categorias de consumidores. A primeira categoria apresenta como termos opostos: os consumidores habituais em oposição aos consumidores eventuais, que estão abertos para comprar e experimentar marcas e produtos diferentes. A segunda categoria propõe como termos opostos: os consumidores com consciência de alta qualidade e os que se contentam com marcas e produtos de boa qualidade. A terceira categoria assinala como termos opostos: os consumidores que percebem diferenças entre as marcas de uma determinada categoria e aqueles outros que não diferenciam as marcas.

Considerando-se as categorias de consumidores, a pesquisa realizada indicou que as marcas são valorizadas por consumidores habituais, os quais percebem diferenças entre as marcas e acreditam que essas sejam indicadoras de qualidade. Portanto, a fidelização dos consumidores e a distinção das marcas, através de todas suas expressões são fatores necessários. É amplo o papel das embalagens neste processo de 
valorização da marca, porque essas são elementos identificadores e distintivos da marca e do produto, apresentando-se, também, como expressão de qualidade e do posicionamento da marca diante do mercado e do público.

O desenvolvimento de projetos e da produção de embalagens caracteriza um setor em pleno desenvolvimento no Brasil, envolvendo um alto faturamento anual. Contudo, há muito ainda por fazer. Por exemplo, no setor brasileiro de alimentos, mais de $20 \%$ dos alimentos produzidos não são distribuídos. A falta ou a ineficiência das embalagens resulta na perda de produtos agrícolas, impedindo o acesso das populações mais pobres (KOSCHAT, 2010).

Por outro lado, os gestores de marcas e produtos ampliam, constantemente e estrategicamente, o papel das embalagens no processo de posicionamento no mercado e na mente dos públicos, internos e externos ao processo corporativo. O Comitê de Estudos Estratégicos da Associação Brasileira de Embalagens (ABRE) informa que, de acordo com pesquisa realizada, o consumidor brasileiro requer embalagens melhores, de maior qualidade, mais expressivas e com melhor design. Para Mestriner (2010), os produtos líderes na maioria das categorias do mercado são aqueles com melhores embalagens.

Os materiais, os processos de produção, as informações e os aspectos estético-simbólicos das embalagens, participam de diferentes questões econômicas, logísticas e comunicativas. Assim, participam da configuração da imagem e do processo de consolidação da reputação positiva da marca no mercado e na sociedade.

Por exemplo, o uso de materiais recicláveis ou que não agridem a natureza, considerando-se todo o processo de produção, uso e descarte das embalagens, promove a percepção positiva da marca, por parte do público consumidor e da sociedade em geral. Mestriner (2010) assinala a prospecção decorrente de uma pesquisa, indicando que, no ano de 2014, o número de embalagens sustentáveis deve chegar a 32\% do total produzido no mercado mundial, sendo que, em 2009, essas embalagens representavam $21 \%$ da produção do setor.

Os aspectos positivos, funcionais e ambientais, das embalagens são percebidos como expressões de qualidade, agregando valor perceptivo-simbólico à marca e ao produto. Todavia, como foi evidenciado neste texto, há aspectos expressivos das embalagens, cujo caráter é originalmente estético. Porém, por associação cultural, esses também são percebidos como sinais de distinção e símbolos de identificação e qualidade.

O investimento da marca Coca-Cola na caracterização e distinção da embalagem de vidro de seu produto promoveu a consolidação de um poderoso símbolo de identificação e distinção. Além de identificar, distinguir e qualificar a marca e o produto, a garrafa do produto Coca-Cola foi consolidada como símbolo da cultura global de mercado, sendo essa desenvolvida e consolidada no século XX e estendida ainda neste século XXI.

A lata do produto leite condensado Moça passou por um amplo processo de distinção e potencialização de sua informação tátil-sensorial e visual. Assim, promoveu as condições para estabelecer uma comunicação mais dinâmica e excitante com o público em geral e com o público consumidor em especial. A ondulação do corpo da embalagem atual é apresentada como elemento de distinção da marca e do produto. Pois, agora, a embalagem e o produto, acondicionado, comunicado e representado na lata 
rotulada, são percebidos de maneira diferenciada com relação aos concorrentes.

Do ponto de vista simbólico, a ondulação da embalagem reforça os sentidos de feminilidade e sensualidade que, tradicionalmente, são relacionados ao nome "Moça" e à figura que representa a mulher jovem. A relação entre a natureza do produto leite e a figura feminina promove significados e sentidos diferentes dos que seriam propostos, por exemplo, pela figura masculina de um leiteiro ou pela representação de um animal, como uma vaca. A ondulação no corpo desta embalagem, devido à natureza $\mathrm{e}$ ao nome do produto, reforça sentidos e significados relacionados ao universo feminino de vida e trabalho. Isso é especialmente referenciado pela representação do avental na figura feminina.

$\mathrm{O}$ formato cilíndrico ondulado da embalagem mais recente do produto leite condensado Moça, seu acabamento polido e brilhante e, ainda, sua composição formal e cromática mais contrastante, com efeitos gráficos sugerindo brilhos e transparências, compõem um discurso sensorial com ênfase na visualidade.

Em comparação com as embalagens mais antigas, o discurso da embalagem atual do produto leite condensado Moça mostra-se mais dinâmico e esteticamente mais atuante. A partir das embalagens anteriores para as mais recentes, a sequência das edições evidencia um incremento constante e crescente na estética brilhante e dinâmica das embalagens. A visualidade das embalagens mais antigas enfatiza a funcionalidade para acondicionar e referenciar objetivamente o produto, contrastando com a ênfase na sedução estético-simbólica da embalagem mais recente.

Tratando-se agora da embalagem de vidro do produto vodka Absolut, considera-se que, simbolicamente, a rigidez clássica do formato da garrafa, o uso de letras cursivas e o timbre em relevo são elementos compensatórios da pouca tradição do país de origem da marca como produtor de vodka. Além disso, o investimento em Design para a distinção da garrafa compensa também as dificuldades de diferenciação objetiva do produto frente à concorrência.

A transparência característica da garrafa de vodka Absolut reforça o discurso que destaca a pureza do produto. A estética minimalista da embalagem de vidro, a tampa de metal acinzentado e a rotulagem impressa diretamente sobre a superfície de vidro, dispensando rótulos de papel ou fundos de tinta, também, distinguem a garrafa com relação às embalagens dos produtos concorrentes mais tradicionais.

Uma rápida pesquisa de imagens de garrafas de vodka na internet evidencia que a garrafa da marca Absolut estabeleceu tendência no design de embalagens deste tipo de produto:

1. Há marcas mais tradicionais que apresentam cores fortes, como azul ou vermelha, com complementos em tons de ouro ou prata no rótulo, na tampa ou em seu revestimento, apresentando ainda símbolos de Heráldica, como brasões, bandeiras ou figuras mitológicas. Assim, essas marcas se posicionam com base na tradição medieval e seus sentidos de nobreza.

2. Há, também, embalagens do produto vodka de outras marcas que apresentam garrafas mais estilizadas e transparentes. Todavia, o desenho da embalagem Absolut, é percebido como pioneiro e modelo do estilo minimalista. A forte imagem da marca sugere ao público que modelos semelhantes são referências à marca líder.

Por sua estética pioneira, como embalagem do produto vodka, podendo ser nitidamente diferenciada, a garrafa de vodka Absolut é um elemento de identificação da marca, que se sobrepõe ao 
próprio nome. Isso foi indicado em uma das edições da embalagem Absolut (Fig. 5-B), com a retirada do elemento gráfico-nominal que caracteriza o logotipo da marca. Além disso, com relação à marca e ao seu produto, a garrafa participa de maneira necessária e predominante na percepção de qualidade do público, devido à qualidade e ao requinte expressos na própria embalagem.

Considerando-se os exemplos de embalagem aqui apresentados, especialmente as embalagens dos produtos Coca-Cola, leite condensado Moça e vodka Absolut, foi possível identificar e ilustrar as possibilidades do design de embalagens no processo de identificação e qualificação da marca e de seu produto. Entre outros aspectos, a qualidade percebida é necessária à plena potência da marca, que é representada pela expressão brand equity. Assim, evidencia-se a necessidade da área de Branding ou Gestão da Marca atuar em conjunto com a área de Gestão de Design, visando desenvolver e gerenciar de maneira eficaz os aspectos funcionais e comunicativos, como qualificadores da embalagem, da marca e de seu produto.

\section{REFERÊNCIAS}

AAKER, A. D. Marcas - Brand equity: gerenciando o valor da marca. São Paulo: Negócio, 1998.

Como construir marcas líderes. São Paulo: Futura, 2000.

ABSOLUT. Sítio Digital. Disponível em www.absolut.com.br. Acessado em 16/03/2012.

CALVER, G. 0 que é design de embalagens? Porto Alegre: Bookman, 2009.

GRACIOSO, Francisco. As marcas são seres mutantes. Revista da ESPM, São Paulo, vol. 11, ano 10, ed. 2, p. 24-39, março/abril 2004.

GLOBO MÍDIA. Sítio Digital. Disponível em http://www.globomidia.net/. Acessado em 16/03/2012.

HALEY, M. Que es el branding? Barcelona; Gustavo Gili, 2009.

KLEIN, N. Sem logo: A tirania das marcas em um planeta vendido. Record, 2002.

KNAPP, Duane E. BrandMindset:fixando a marca. Rio de Janeiro: Qualitymark, 2002. 320p

LOTI, Thiago. As inovadoras garrafas de AbsolutVodka. nov. 2010; Disponível em:

$<$ http://facingpages.com.br/?p=5134>. Acesso em 07 maio 2011.

MARTINS, J. R. Branding: o manual para você criar, gerenciar e avaliar marcas. São Paulo: Globalbrands, 2006.

MARTINS, R. A Gestão de Design como Estratégia Organizacional. Londrina: Eduel, 2008.

MESTRINER, F. Design de Embalagem: Curso Básico. São Paulo: Makron Books, 2002.

Design de Embalagem: Curso Avançado. São Paulo: Pearson Prentice Hall, 2005.

. Gestão Estratégica de Embalagem. São Paulo: Prentice Hall, 2007.

HSM Online. A contribuição social da embalagem. Disponível em: http://br.hsmglobal.com/notas/54908a-contribuicao-social-da-embalagem.

Acesso em 15 de Maio de 2010.

. Embalagem sustentável. Disponível em: http://br.hsmglobal.com/notas/53395embalagens-sustentaveis. Acesso em 15 de Maio de 2010.

Portal ESPM. Embalagem é tudo. Disponível em: 
http://embalagem.espm.br/web/guest/embalagemetudo.Acesso em 15 de Maio de 2010.

MUNDO DO MARKETING. Sítio digital. Disponível em http://www.mundodomarketing.com.br/. Acessado em 16/03/2012.

NESTLÉ. Sítio digital. Disponível em http://www.nestle.com.br. Acessado em 16/03/2012.

PERASSI, Richard. Gramática comparada da representação gráfica. In: Revista Convergências. Lisboa. N. 6, V. 1, 2010. Disponível em http://convergencias.esart.ipcb.pt/artigo/92.

PINHO, J.B. 0 poder das marcas. São Paulo: Summus, 1996.

OGLIVY, David. Confissões de um Publicitário. São Paulo: Bertrand Brasil, 2001.

SAMPAIO, Rafael. Marcas de A a Z: como construir e manter marcas de sucesso. Rio de Janeiro: Campus, 2002.

SCHLEMPER, P. A contribuição do design gráfico como materializador da identidade de marca, no aumento do valor de marca agregado ao produto. Florianópolis, 2004. Dissertação (Mestrado em Engenharia da Produção). Pós Graduação em Engenharia da Produção, Universidade Federal de Santa Catarina.

SCHMITT, Bernd e SIMONSON, Alex. A estética do marketing: Como criar e administrar sua marca, imagem e identidade. São Paulo: Nobel, 2000. 343 p.

STRUNCK, G. Como criar identidades visuais para marcas de sucesso. Rio de Janeiro: Rio Books, 2007.

VIDRADO. COM. Coca-Cola relança primeiras garrafas de vidro na Grã-Bretanha. Disponível em http://noticias.vidrado.com/mercado-e-negocios/coca-cola-relanca-primeiras-garrafas-de-vidro-na-grabretanha/ Acessado em 16/03/2012.

WHEELER, A. Design de Identidade da Marca: um guia completo para criação, construção e manutenção de marcas fortes. Porto Alegre: Bookmann, 2008.

WORDPRESS. Co-branding: estilistas e designers vestem as famosas garrafas da Coca-Cola. Disponível em http://estrategiaempresarial.wordpress.com/2008/08/18/co-branding-estilistas-e-designers-vestem-asfamosas-garrafas-da-coca-cola/ Acessado em 16/ 